\title{
Coping with Information Load: User Strategies and Implications for Librarians
}

\author{
Joel Rudd and Mary Jo Rudd
}

The major purpose of this paper is to describe important techniques by which library users avoid information overload. The paper also clarifies the terminology in the information load literature and reviews its major findings. The paper applies these findings to a library context and discusses their implications for users and librarians.

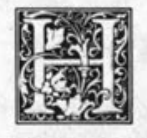

ow are library users handling the increasing amounts of information available to them in college and research libraries? This question has drawn the attention of numerous commentators in recent years. ${ }^{1.5}$ While some have expressed concern that the increased amount of information in libraries may have a negative impact on users, i.e., may "overload" them, ${ }^{6}$ others believe that users do quite well through use of any of several "coping mechanisms." open one, in part because so little empirical library research has been conducted in this area. Instead, we must rely mainly on the findings from information load research performed in fields other than library science, e.g., clinical psychology and consumer behavior. In addition, there is considerable conceptual and definitional ambiguity apparent in the use of important terms. After clarifying these ambiguities and reviewing what empirical researchers have discovered about the impact of increasing amounts of information on users, the present paper applies these findings to a library context and discusses the implications of these findings for users and librarians.

\section{CONCEPTUAL AND DEFINITIONAL AMBIGUITIES}

Terms such as information explosion and information overload (less frequently used terms include information glut, communication explosion, and communications overload) are too often used ambiguously. ${ }^{8-10}$ Sometimes these terms are used interchangeably when they should be used to denote quite separate concepts.

The term information explosion should be used only to describe an extreme increase in the supply of information available to library users. While there is agreement that the amount of information stored in libraries has been growing very rapidly (perhaps even at an explosive rate), ${ }^{11,12}$ there is some disagreement over the effect on library users of this increased information supply. ${ }^{13,14}$

In order to clarify the possible effects of an increase in information supply on library users, two additional terms, information load and overload, must be consensually defined. The term information load should be reserved for that amount of information actually acquired by a processing system, e.g., a library user. An increase in the supply of information

Joel Rudd is associate professor at the School of Family and Consumer Resources, University of Arizona, Tucson, Arizona 85721. Mary Jo Rudd is formerly assistant librarian and cataloger, University Libraries, Arizona State University. The authors wish to acknowledge the helpful comments of the editor and two anonymous reviewers on an earlier draft. 
available in libraries does not necessarily produce an increase in the information load carried by library users. ${ }^{15}$ When an increase in information supply does result in an increased information load for library users, three effects are possible. First, such an increase in load may produce an overload effect in users, with resultant confusion, tuning out of some information, decreased quantity and/or quality of output, or in extreme cases, system shutdown. Second, an increase in information load may result, through a variety of coping mechanisms, in the user processing the increased information in such a way as to enhance the quantity and/or quality of output. Third, an increase in information load may result, again through a variety of mechanisms, in no discernible effect on the library user.

It is clear that to be useful, theoretical and policy statements must distinguish between the effects expected to result from an increase in (1) the amount of information available to users, and (2) the amount (load) users process or attempt to process. It appears likely that the effect of the latter is largely independent of change in the former. Further, virtually the only way users can be affected by changes in information available is when (or if) these changes effect a change in users' information load.

\section{INFORMATION LOAD RESEARCH}

In this section we briefly review the information load literature to ascertain what researchers have learned about the effect of increased information load on users. As will become apparent, research findings vary considerably. Some studies report that increased information loads produce information overload, while others indicate that more information has positive effects on users.

Among the earliest systematic studies of the effects of increased information loads were psychological experiments performed by James Miller and colleagues. ${ }^{16}$ In these experiments information load was conceptualized as the amount of information input into a system (a human subject) in a given period of time. In gen-

\section{July 1986}

eral, as information load increased, the amount of information output at first increased and then, at quite high levels of input, decreased. In a few instances, information output did not decline at high input levels. ${ }^{17}$

Another series of psychological experiments concerned the effects of increased information load on small decisionmaking groups. Once again, information load was defined as the amount of information presented per unit of time. In some of these experiments, increased information load produced an overload effect; i.e., the quality of group decisions declined at higher input levels. ${ }^{18}$ In others, increased information load resulted in increased group decision accuracy. ${ }^{19}$ Still others found that as input increased, group output increased, and then at high input, leveled off. ${ }^{20}$

Early studies of the effects on consumer decision making of various information loads reported that at high input levels, consumer decision quality declined. ${ }^{21}$ However, statistical reanalyses of these early data and later research have indicated that, in general, increased information loads produce higher-quality consumer decision making. ${ }^{22-24}$ It should be noted that, in these studies, consumers were not under explicit time constraints: they could take as much time as they wished to process the information.

A number of studies have been conducted on the effects of various amounts of information on diagnostic judgment made by clinical psychologists. Only one study in this research paradigm has reported an overload effect. ${ }^{25}$ The majority of studies indicate that as information loads increase, predictive accuracy either increases or remains level. ${ }^{26,27}$ Again, there were no explicit time constraints.

The management literature contains several information load studies. Here, too, the results are mixed. Several studies report that increased information produces an overload effect, ${ }^{28,29}$ while others found superior management performance to result. ${ }^{30}$

The library/information science literature contains one piece of empirical research on the effect of increased informa- 
tion load on library users. Susan Emerson and Linda Cooper present three case studies of decision making by users under high information input levels. ${ }^{31}$ In all three cases, users refined their decision-making processes (i.e., employed coping mechanisms) in the face of high levels of information. Neither the quality of the decision nor the quality of the decision-making process were measured in these case studies.

\section{USER STRATEGIES AND IMPLICATIONS FOR LIBRARIANS}

In those instances when increased information load does not produce overload effects, users may be engaging (intentionally or not) in actions to prevent overload from occurring. It seems clear that information users are doing much more than merely reacting to overload in a post hoc fashion. Instead, they frequently appear to be avoiding overload in the first place. Processes and techniques for avoiding overload are legion. In this section, we will discuss the most common ones, concentrating on those most applicable in a library context. The implications of these user strategies for librarians are also discussed.

One of the most common methods by which users avoid overload is through use of various decision heuristics or rules of thumb. ${ }^{32}$ As tools employed by users to reduce complex tasks to simpler operations, heuristics frequently involve limitations on information acquisition. Many heuristics follow Herbert Simon's "satisficing" principle: rather than maximizing information acquisition, users acquire only a "satisfactory" subset of the amount of information available. ${ }^{33}$ In part, the use of satisficing heuristics reflects the operation of the law of diminishing returns: users frequently recognize that the amount of new information acquired diminishes as additional information sources are accessed. As an example of a satisficing heuristic, library users may limit their information acquisition by following a rule of thumb stating that they will acquire and process only topical information published since 1980. Most bibliographic tools are designed to allow for the operation of a satisficing heuristic based on date, keyword, and a number of other characteristics.

Another common rule of thumb consistent with the satisficing principle is called "skimming off the top.", ${ }^{43,35}$ This heuristic states: "Process only the first few pieces of information accessed, then stop." In some instances, various characteristics of the library collection may serve to define those "first few pieces of information." For example, the set of information acquired under this heuristic might be delimited as "all topical items in the library collection cataloged under a particular heading and currently accessible." In other instances, this heuristic operates to limit not the amount of information acquired but rather how thoroughly the information sources are processed. For example, relatively large amounts of information may be acquired in broad sweeps, but the detail contained therein may be ignored. The widespread use of satisficing heuristics by library users helps us to understand why so little of most library collections is ever used. Most information in libraries goes unaccessed simply because users are satisfied to acquire far less than the maximum.

There is a special sort of user activity that is related to the use of heuristics. Users frequently employ "chunking" to acquire and store relatively large amounts of information without risking overload. Chunking refers to a cognitive process of categorizing or organizing otherwise discrete pieces of information into "chunks" that are readily held in memory. ${ }^{36,37}$ Chunking allows library users to scan a piece of material and categorize it in a useful shorthand. The use of such shorthand enables users to process much larger amounts of information than would otherwise be possible and to do so without risking the negative effects of information overload. Thus the reader of this paper may chunk the paragraph just read as "the chunking section."

To some extent, avoiding or minimizing time constraints can help users avoid overload. On a pragmatic level, this simply means that users should allow them- 
selves (or demand that they be allowed) sufficient time to deal with the information task at hand. Novice users often have little idea of how much time the information task facing them will take. Further, it is likely that many users tend to underestimate the amount of time a particular task will take. To help avoid or minimize time constraints, both users and librarians should strive to minimize the amount of user time spent on "extraneous" activities. For example, the practice of many institutions of building numerous satellite libraries housing particular collections forces both users and librarians to engage in extraneous activities. For users, a primary extraneous activity occurs when, while in the main library, they discover that the item needed is in a satellite library. For librarians, additional cataloging, as well as physically transporting items from library to library, provides significant extraneous activities.

Further, it sometimes appears to users that librarians' development, use, and continued refinement of classification and storage systems within a particular library building only make the users' information acquisition tasks more inefficient. ${ }^{38}$ Stephen Stoan discusses several library classification and storage policies that have unintended consequences for user information, information acquisition, and processing efficiency. ${ }^{39}$ The classification of journals, for example, makes browsing related journals for information a much more time-consuming task. Further, storing journals or other material on microfilm makes acquisition of endnote information very inefficient because of the need to continually reel back and forth.

Regardless of classification, storage, or other factors, users must also avail themselves of and refine their abilities to select and evaluate information efficiently and effectively. The ability and willingness (sometimes with great ruthlessness) to acquire selectively only a subset of available information are valuable means to avoid overload. Empirical evidence of this process is found in Emerson and Cooper's case studies of library users. ${ }^{40}$ Emerson and Cooper reported that users screened information and zeroed in on a small aspect of the problem to avoid overload.

This technique of selective acquisition can be applied by collectives as well as by individuals. The increased specialization among professionals, especially in research and development, provides a good example of selective acquisition. Part of the training of modern researchers and scholars includes explicit rejection of massive amounts of related information "outside one's literature." This process, called "twigging," describes a technique whereby people deal with increased information availability by "branching off" or "selecting a turf" and exploring information only within those bounds.

Early experiments on the psychology of information load frequently did not find these kinds of screening activities because they were not looked for. These studies borrowed an extremely mechanical view of information and information processing from the classic information theory of electrical engineering. ${ }^{42}$ In this view, information processing systems (e.g., people) are passive receivers of information with "limited channel capacity," unable to control or affect input levels. ${ }^{43}$ Operationally, this has meant that many, if not most, information load experiments have not allowed people to acquire information ad lib, nor have they allowed them to screen the information they were to process. Rather, users have been forced to input and process a given quantity and quality of information in a given period of time. As a number of critics have pointed out, ${ }^{44}$ these conditions are simply not representative of most human information processing: people are not passive sponges, soaking up information. Rather, they actively select and evaluate available information in fairly sophisticated ways. As Karl Weick notes, people balance their "need for knowledge with [their] capacity to absorb it" and may selectively acquire information on this basis. ${ }^{45}$

A fourth technique for avoiding overload is conceptually related to the chunking process. Craig Dudzak argues that users may avoid overload by using "generic frames of reference. ${ }^{\prime 46}$ These are analo- 
gous to a series of standard term paper outlines into which users can readily plug new information. Unlike the more freeform and emergent chunks, these preexisting frames of reference have a standard form. They allow users to process new information by fitting it to the outline and later to access it efficiently from the outline.

Users may also avoid information overload by perceiving the gestalt of the information they are acquiring. This largely noncognitive process is, as yet, not well understood. It appears to be one of many right-hemispheric brain activities that are image- rather than information oriented. The user somehow develops an overall image by perceiving information as large patterns. Preliminary evidence of this process among users is provided by Sally Power-Ross, who studied the information acquisition patterns of securities portfolio managers. ${ }^{47}$ Despite the massive amount of information available, Power-Ross found no evidence of information overload. Neither did she find evidence of any of the common cognitive techniques for avoiding overload. Power-Ross explains these findings in terms of brain hemispherics: the right brain, using images rather than words, acquires large amounts of information and processes it as patterns.

Another avenue available to library users that may help them avoid overload is enrollment in bibliographic and/or general library skills courses. Many courses covering such material are designed to help users avoid overload. Certainly these courses are explicitly designed to help make the collection more accessible to users and to produce more efficient and effective information gatherers. Thus, these courses may, for example, help users to minimize the amount of time they spend on extraneous activities.

Bibliographic and library instruction have been controversial topics since their origin more than a century ago. ${ }^{48}$ One of the debates in this area concerns the complex relationships between the intended audience for these courses (users) and their teachers (librarians). While evidence exists that both students and faculty can be successfully taught bibliographic and other library skills, ${ }^{49,50}$ these audiences have not always been receptive to the idea. ${ }^{51,52}$ Anne Lipow notes that faculty had to be gently "tricked" into attending bibliographic instruction. The most common incentive used to get students into such a course is to offer it for university credit. $^{53}$

Anecdotal evidence is widely available indicating that both students and faculty (prior to bibliographic/library instruction) avoid overload largely by either avoiding the library or, once in the library, spending little time in the information search and giving up quickly. ${ }^{54}$ This strategy of avoiding overload by avoiding the collection is but one example of a more general technique for avoiding overload. This technique involves avoiding formal (e.g., bibliographic sources) information acquisition altogether and, instead, acquiring information from informal sources. ${ }^{5,56}$ Acquisition of information from informal sources affords users a greater level of control over the amount of information to be acquired. Informal sources include footnotes and reference lists in journals and books, correspondence and conversation with colleagues, and presented papers. Use of such informal sources is particularly common among mature scholars; those struggling to use the formal bibliographic sources are more likely to be graduate students and other "beginners." There is considerable debate about whether and/or to what extent librarians ought to be making material efforts to draw mature scholars into the library. As Stoan points out, such scholars bring with them considerable research skills, but often lack the fundamentally different bibliographic/library skills. Librarians must be cautious, Stoan warns, to avoid making changes in library policy that might hinder the research process; e.g., arranging journals by classification largely eliminates browsing.

A final technique for avoiding overload is to delegate some or all of the information acquisition and analysis tasks to others. The use of graduate students for such 
purposes is well known. ${ }^{58}$ Some occupational categories consist of people trained to acquire and analyze information for others, (e.g., travel agents and financial planners). Some librarians serve such a function; in other cases, information brokers serve to link information providers (e.g., online databases) with information users. $^{59}$

The extent to which librarians can or should perform the function of information brokers is a topic of current debate. ${ }^{60}$ As information availability continues to grow with the increase in computer databases and catalogs, librarians may find themselves increasingly pressured to assume such a role. ${ }^{61}$ On the other hand, it may be even more informationally efficient for users themselves to have direct access to the computer-based information. Our understanding of search theory and search processes is very limited: much work remains to be done in this area. Research that builds on the work of Marcia Bates ${ }^{62}$ and Peter Vigil ${ }^{63}$ would be a welcome addition to the literature. In the meantime, both information brokers and users appear likely to continue using a variety of available techniques to avoid information overload.

\section{THE FUTURE}

The present paper has discussed some of the numerous techniques current among library users to avoid information overload. As the amount of information in libraries continues to increase, an awareness on the part of librarians of mechanisms for avoiding overload will become increasingly important. Librarians are in a unique position to act as information brokers and to train users in techniques for avoiding overload. For example, some commentators appear to view the computerization of databases and cataloging as part of the information overload problem. In our view, computerization will, in the near future, be recognized as a major way library users can access larger amounts of information more efficiently than ever before. Many of the basic techniques for avoiding overload will be enhanced when computers are available to users (either in the library or at remote sites). In addition, future instruction in bibliographic and library skills (perhaps including explicit attention to techniques for avoiding overload) will be more efficient and effective when presented on computer.

\section{REFERENCES AND NOTES}

1. Susan Artandi, "Man, Information, and Society: New Patterns of Interaction," Journal of the American Society for Information Science 30:15-18 (Jan. 1979).

2. Lester Asheim, "Ortega Revisited," Library Quarterly 52:215-26 (July 1982).

3. Murray Bob, "The Information Age: Mis-, Dis- and Overload; One Librarian's View," Bookmark 41:61-64 (Winter 1983).

4. Evelyn Daniel, "Special Librarian to Information Manager," Special Libraries 73:93-99 (Apr. 1982).

5. Herman H. Fussler and Karl Kocher, "Contemporary Issues in Bibliographic Control," Library Quarterly 47:237-52 (July 1977).

6. Asheim, "Ortega Revisited."

7. Ithiel de Sola Pool and Herbert I. Schiller, "Perspectives of Communications Research: An Exchange," Journal of Communication 31:15-23 (Summer 1981).

8. Asheim, "Ortega Revisited."

9. Robert Goehlert, "Information, Persuasion and Freedom: Implications of Communication Technology," Information Processing and Management 16:109-14 (1980).

10. Harry S. Havens, "Decision Information and the Decision-Maker," in Information Technology Serving Society, ed. Robert Lee Chartrand and James W. Morentz, Jr. (Elmsford, N.Y.: Pergamon Pr., 1979), p.61-63.

11. Artandi, "Man, Information and Society."

12. Orrin E. Klapp, Opening and Closing: Strategies of Information Adaptation in Society (Cambridge: Cambridge Univ. Pr., 1978).

13. C. Edward Wilson, "Information Discrimination: A Human Habit," Canadian Journal of Information Science 1:59-64 (May 1976). 
14. Jose Ortega y Gassett, "The Mission of the Librarian," Antioch Review 21:133-54 (Spring 1961).

15. Richard L. Meier, "Communications Overload: Proposals from the Study of a University Library," Administrative Science Quarterly 7:521-44 (Mar. 1963).

16. James Grier Miller, Living Systems (New York: McGraw-Hill, 1978).

17. Ibid.

18. Harold M. Schroder, Michael J. Driver, and Siegfried Streufert, Human Information Processing (New York, N.Y.: Holt, 1967).

19. Avner M. Porat and John A. Haas, "Information Effects on Decision Making," Behavioral Science 14:98-104 (1969).

20. James G. Miller, "Information Input Overload and Psychopathology," American Journal of Psychiatry 116:695-704 (1960).

21. Jacob Jacoby, Donald E. Speller, and Carol Kohn Berning, "Brand Choice Behavior as a Function of Information Load: Replication and Extension," Journal of Consumer Research 1:33-42 (June 1974).

22. Naresh K. Malhotra, Arun K. Jain, and Stephen W. Lagakos, "The Information Overload Controversy: An Alternative Viewpoint," Journal of Marketing 46:27-37 (Spring 1982).

23. J. Edward Russo, "More Information Is Better: Reevaluation of Jacoby, Speller and Kohn," Journal of Consumer Research 1:68-72 (Dec. 1974).

24. George B. Sproles, Loren V. Geistfeld, and Suzanne B. Badenhop, "Types and Amounts of Information Used by Efficient Consumers," Journal of Consumer Affairs 14:37-48 (Summer 1980).

25. C. J. Bartlett and Calvin G. Green, "Clinical Prediction: Does One Sometimes Know Too Much?" Journal of Counseling Psychology 13:267-70 (1966).

26. Albert Kostlan, "A Method for the Empirical Study of Psychodiagnosis," Journal of Consulting Psychology 18:83-88 (1954).

27. Melvin L. Schwartz, "Validity and Reliability in Clinical Judgement of C-V-S Protocols as a Function of Amount of Information and Diagnostic Category," Psychological Reports 20:767-74 (1967).

28. Norman L. Chervany and Gary W. Dickson, "An Experimental Evaluation of Information Overload in a Production Environment," Management Science 20:1335-44 (June 1974).

29. Charles A. O'Reilly, III, "Individuals and Information Overload in Organizations: Is More Necessarily Better?" Academy of Management Journal 23:684-96 (1980).

30. Henry C. Lucas, Jr., and Norman R. Nielsen, "The Impact of the Mode of Information Presentation on Learning and Performance," Management Science 26:982-93 (1980).

31. Susan V. Emerson and Linda E. Cooper, "The Stress Curve as a Representation of the Effect of Information Input on the User's Productivity," in Productivity in the Information Age; Proceeding of the ASIS Annual Meeting, ed. Raymond F. Vondran and others (White Plains, N.Y.: Knowledge Industry, 1983), p.14-18.

32. Steven J. Sherman and Eric Corty, "Cognitive Heuristics," in Handbook of Social Cognition, V.1, ed. Robert S. Wyer, Jr., and Thomas K. Srull (Hillsdale, N.J.: Lawrence Erlbaum Assoc., 1984), p.189-286.

33. Herbert A. Simon, Models of Thought (New Haven, Conn.: Yale Univ. Pr., 1979).

34. Emerson and Cooper, "The Stress Curve."

35. James G. Miller, "Living Systems: Structure and Process," Behavioral Science 10:337-99 (1965).

36. Emerson and Cooper, "The Stress Curve."

37. Miller, "Living Systems."

38. Asheim, "Ortega Revisited."

39. Stephen K. Stoan, "Research and Library Skills: An Analysis and Interpretation," College \& Research Libraries 45:99-109 (Mar. 1984).

40. Emerson and Cooper, "The Stress Curve."

41. Karl E. Weick, "The Twigging of Overload," in People and Information, ed. Harold B. Pepinsky (New York: Pergamon Pr., 1970), p.67-129.

42. C. E. Shannon and W. Weaver, A Mathematical Theory of Communication (Urbana, Ill.: Univ. of Illinois Pr., 1949).

43. Miller, Living Systems.

44. Z. J. Lipowski, "Sensory and Information Inputs Overload: Behavioral Effects," Comprehensive Psychiatry 16:199-221 (May/June 1975).

45. Weick, "The Twigging of Overload."

46. Craig A. Dudzak, "Coping with Information Overload as Adaptive Behavior in Competitive Debate," paper presented at the Annual Meeting of the Western Speech Communication Association, ERIC Document Reproduction Service, ED 240 658, 1984.

47. Sally J. Power-Ross, "The Information Acquisition Style and Decision Making Mode of HighLevel Managers in an Information Rich Environment," paper presented at the Annual Meeting of 
the Speech Communication Association, ERIC Document Reproduction Service, ED 249 552, 1984.

48. John Mark Tucker, "The Origins of Bibliographic Instruction in Academic Libraries, 1876-1914," New Horizons for Academic Librarians, ed. Robert D. Stueart and Richard D. Johnson (New York: K. G. Saur, 1979), p.268-76.

49. Anne Grodzins Lipow, "Teaching the Faculty to Use the Library: A Successful Program of InDepth Seminars for University of California, Berkeley, Faculty," in New Horizons for Academic Librarians, ed. Robert D. Stueart and Richard D. Johnson (New York, K. G. Saur, 1979), p.262-67.

50. Richard J. Wood, "The Impact of a Library Research Course on Students at Slippery Rock University," Journal of Academic Librarianship 10:278-84 (Nov. 1984).

51. Lipow, "Teaching the Faculty."

52. Constance McCarthy, "The Faculty Problem," Journal of Academic Librarianship 11:142-45 (July, 1985).

53. Wood, "The Impact of a Library Research Course."

54. Stoan, "Research and Library Skills."

55. J. M. Brittain, "Pitfalls of User Research, and Some Neglected Areas," Social Science Information Studies 2:139-48 (July 1982).

56. Stoan, "Research Library Skills."

57. Ibid.

58. Klapp, Opening and Closing.

59. Emerson and Cooper, "The Stress Curve."

60. Daniel, "Special Librarian."

61. Norma Ruth Torkelson, "SDI as a Control of Information Overload," Innovative Developments in Information Systems: Their Benefits and Costs; Proceeding of the ASIS Annual Meeting, ed. Helen J. Waldron and F. Raymond Long (Washington, D.C.: American Society for Information Science, 1973), p.231-32.

62. Marcia J. Bates, "Search Techniques," in Annual Review of Information Science and Technology, ed. Martha E. Williams (V.16, 1981), p.139-69.

63. Peter J. Vigil, "The Psychology of Online Searching," Journal of the American Society for Information Science 34:281-87 (July 1983).

\section{IN FORTHCOMING ISSUES OF COLLEGE \& RESEARCH LIBRARIES}

Selected Papers, Part II, from the ACRL Fourth National Conference, Baltimore, April 9-12, 1986

The Federal Information Controversy from an Economic Perspective by Thelma Freides Performance Appraisal: Is It Working? by Charles A. Schwartz

The Managerial Roles of Academic Library Directors by Michael Ann Moskowitz Book Availability at the University of California-Santa Cruz by Terry Ellen Ferl and Margaret G. Robinson 